\title{
Species at Risk (SPEAR) index indicates effects of insecticides on stream invertebrate communities in soy production regions of the Argentine Pampas
}

Hunt, L. ${ }^{1}$, C. Bonetto ${ }^{2}$, N. Marrochi ${ }^{2}$, A. Scalise, S. Fanelli ${ }^{2}$, M. Liess ${ }^{3}$, M.J. Lydy ${ }^{4}$, M.-C. Chiu ${ }^{1}$, and V.H. Resh ${ }^{1}$

${ }^{1}$ University of California, Berkeley, Department of Environmental Science, Policy \& Management, Berkeley CA 94720-3114 USA. ${ }^{2}$ ILPLA (CONICET-CCT La Plata) - UNLP Instituto de Limnología "Dr. Raúl. A. Ringuelet", Boulevard 120 y 62, La Plata (1900), Buenos Aires, Argentina. ${ }^{3}$ Helmholtz Centre for Environmental Research, System-Ecotoxicology, Leipzig, Germany. ${ }^{4}$ Center for Fisheries, Aquaculture and Aquatic Sciences, Department of Zoology, Southern Illinois University, Carbondale, IL 62901.

\begin{abstract}
We investigated relationships among insecticides and aquatic invertebrate communities in 22 streams of two soy production regions of the Argentine Pampas over three growing seasons. Chlorpyrifos, endosulfan, cypermethrin, and lambda-cyhalothrin were the insecticides most frequently detected in stream sediments. The Species at Risk (SPEAR) pesticide bioassessment

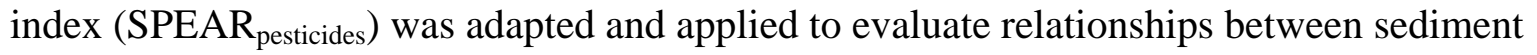
insecticide toxic units (TUs) and invertebrate communities associated with both benthic habitats

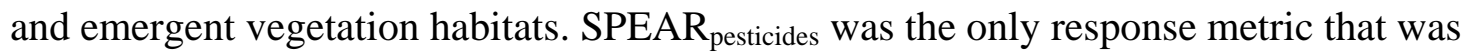
significantly correlated with total insecticide TU values for all three averaged data sets, consistently showing a trend of decreasing values with increasing TU values $\left(\mathrm{r}^{2}=0.35\right.$ to 0.42 , p-value $=0.001$ to 0.03$)$. Although pyrethroids were the insecticides that contributed the highest
\end{abstract}


TU values, toxicity calculated based on all insecticides was better at predicting changes in invertebrate communities than toxicity of pyrethroids alone. Crustaceans, particularly the amphipod Hyalella spp., which are relatively sensitive to pesticides, played a large role in the

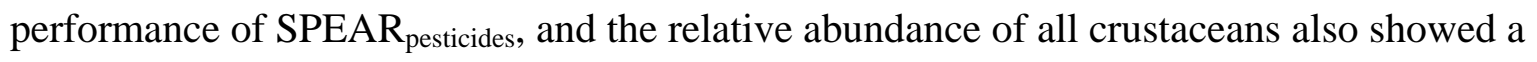
significant decreasing trend with increasing insecticide TUs for two of three data sets $\left(\mathrm{r}^{2}=0.30\right.$ to $0.57, \mathrm{p}$-value $=0.003$ to 0.04 ) examined. For all data sets, total insecticide TU was the most important variable in explaining variance in the $\mathrm{SPEAR}_{\text {pesticides }}$ index. The present study was the first application of the SPEAR index in South America, and the first one to use it to evaluate effects of pesticides on invertebrate communities associated with aquatic vegetation. Although the SPEAR index was developed in Europe, it performed well in the Argentine Pampas with only minor modifications, and would likely improve in performance as more data are obtained on traits of South American taxa, such as pesticide sensitivity and generation time.

\section{Keywords}

Insecticides; Soybean production; Stream bioassessment; Aquatic toxicity; Macroinvertebrates 


\section{Introduction}

The Argentine Pampas, the central plain of Argentina, has a mild climate and very fertile soil. Previously covered by grasslands, it is now the most productive agricultural region of the country. Over the last several decades, soybeans have become a major export crop for Argentina, and increased pesticide use has led to concerns about environmental effects. Between 1995 and 2011, soy cultivation area expanded by 209\% in Argentina (Castanheira and Freire, 2013). Pesticide consumption in Argentina increased from 6 million kilograms in 1992 (Pengue, 2000) to 32 million kilograms in 2012 (CASAFE, 2013). Insecticide application rates are approximately double those of fungicides, and the insecticides most frequently used in soy production (pyrethroids, chlorpyrifos, and endosulfan) have very high aquatic toxicity (Hunt et al., 2016; Nordborg et al., 2014).

Multiple studies have detected soy production insecticides in both sediment and water collected from streams in Argentina (Di Marzio et al., 2010; Hunt et al., 2016; Jergentz et al., 2005; Marino and Ronco, 2005; Mugni et al., 2011), but there is a lack of field studies investigating effects to aquatic invertebrate communities. Several studies in Argentina have found associations 
between stream insecticide concentrations and effects on the native amphipod Hyalella curvispina using single-species toxicity tests (Di Marzio et al., 2010; Jergentz et al., 2004a; Mugni et al., 2011). Also, Jergentz et al. (2004b) found that a pulse of endosulfan was associated with reductions in abundances of Odonata and Ephemeroptera in two small Pampas streams. However, to date no study in the region has documented widespread insecticide effects on aquatic invertebrate communities.

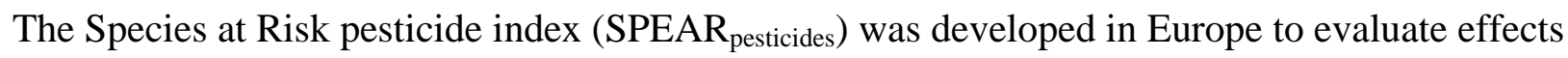
of pesticides on benthic macroinvertebrate communities (Liess and Von der Ohe, 2005), and has been applied successfully in several continents (Schäfer et al., 2012). Significant correlations

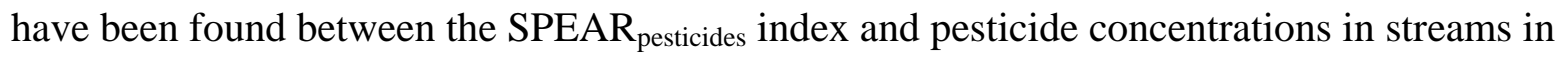
eight countries in Europe, as well as in Australia and Siberia $\left(\mathrm{r}^{2}\right.$ between 0.62 and 0.68) (Schäfer

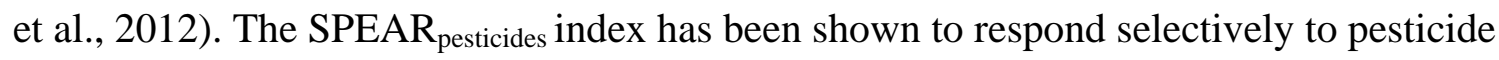
stressors and to be relatively insensitive to most other stressors, although its performance can be affected by severe habitat degradation (siltation and channelization) and low dissolved oxygen (Liess et al., 2008; Münze et al., 2015; Orlinskiy et al., 2015; Rasmussen et al., 2011; Schäfer et al., 2011, 2007).

The objectives of the present study were to: (1) evaluate relationships between insecticide concentrations in stream sediments and aquatic invertebrate communities of the Argentine Pampas using the SPEAR index; (2) examine the major changes in invertebrate communities associated with pesticide exposure; and, (3) test the applicability of the SPEAR index to invertebrate communities associated with both benthos and emergent vegetation. 


\section{Methods and Materials}

\section{Study Locations and Sampling Schedule}

We carried out the study over a three-year period (Dec 2011 - Feb 2014), monitoring 23 sites in small streams located in two regions of the Argentine Pampas, including an intensive soy production region and a mixed agriculture and livestock region (Figure 1; Table S1). In the La Plata region, the principal land use was cattle grazing, with scattered plots of soy production and other agriculture. In the Arrecifes region, intensive soy production was the predominant land use. In the La Plata region, seven sites were sampled during two monitoring events in the 2011 to 2012 soybean growing season, including four sampling sites in one watershed and the remaining three sites in separate watersheds. In the Arrecifes region, 16 sites were sampled over three years (2012-2014) during the soybean growing season, and all sampling sites were on tributaries of the Arrecifes River. 


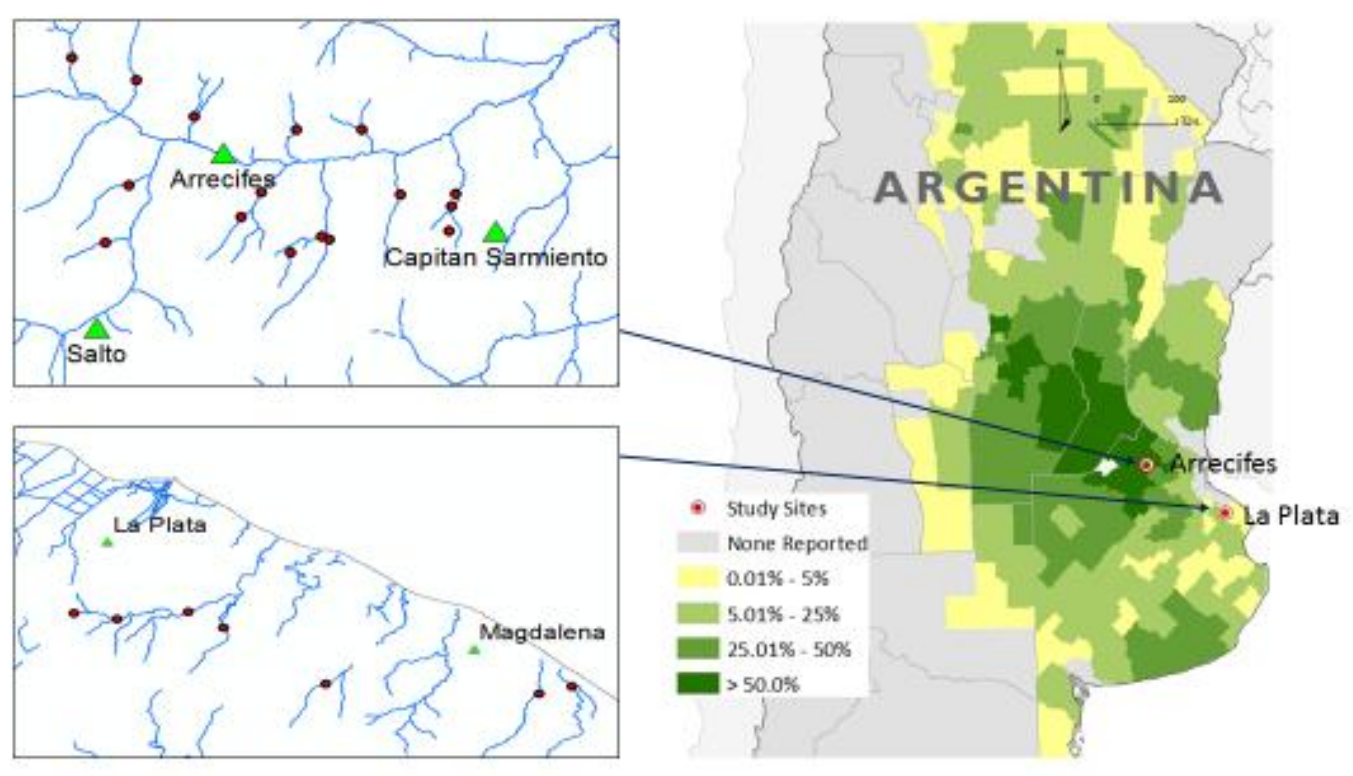

Figure 1. Overview of study regions and soy production intensity in Argentina, and stream sampling locations in the La Plata and Arrecifes regions. Soy production intensity as percent of total land use by province based on government reported data: http://www.minagri.gob.ar.

Catchments were delineated using topographical maps to estimate catchment size (Table S2). Substrates in streams of both regions generally consisted of sediment with no rocks and little woody debris, although a few sites in Arrecifes contained some gravel. Stream depths ranged from about $0.6 \mathrm{~m}$ to $>2 \mathrm{~m}$ (only two sites, both in the La Plata region, were $>1 \mathrm{~m}$ deep), and widths ranged from about $3 \mathrm{~m}$ to about $25 \mathrm{~m}$ (Table S2). Most streams included emergent (e.g. Typha spp. and Scirpus spp.) and submerged vegetation (e.g. Potamogeton, Ceratophyllum, and Egeria), and many in the La Plata region were also characterized by abundant floating vegetation (e.g. Eichornia, Lemna, and Azolla). 
Biological, physico-chemical, and insecticide concentration components involved concurrent stream sampling that was generally timed to occur within a week after a heavy rainfall during or soon after the peak insecticide application period, which usually occurs between December and March. During the 2011-2012 growing season, samples in the La Plata region were collected in December 2011 and March 2012, and in the Arrecifes region in January and March 2012. During 2013 and 2014, samples were collected only in Arrecifes, in February of both years (Table 1). 


\section{Table 1. Invertebrate sample groups for SPEAR threshold optimization and regression analysis.}

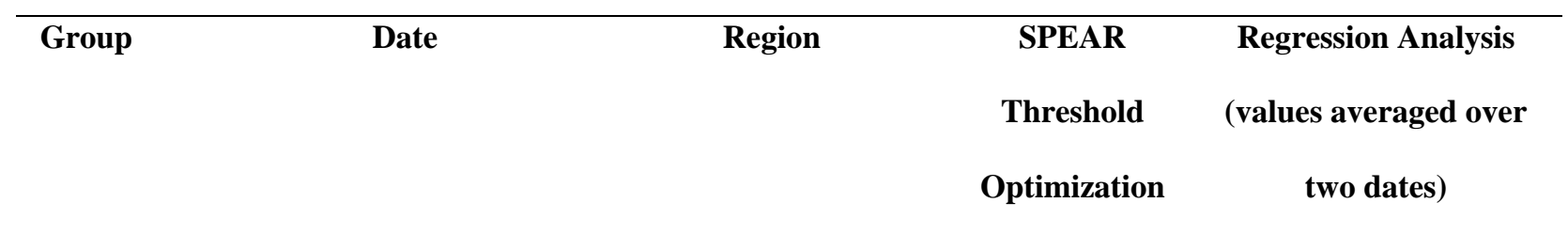

\section{Benthos Samples}

A $\quad$ Dec $2011 \quad$ La Plata $(\mathrm{n}=7)$

\begin{tabular}{ccccc} 
& Jan 2012 & Arrecifes $(\mathrm{n}=5)$ & $\mathrm{n}=12$ & $\mathrm{n}=14^{\mathrm{a}}$ \\
\hline B & March 2012 & La Plata $(\mathrm{n}=5)$ & \\
& & $\mathrm{n}=12$ & \\
\hline C & Frrecifes $(\mathrm{n}=7)$ & & \\
\hline D & Feb 2013 & Arrecifes $(\mathrm{n}=12)$ & $\mathrm{n}=12$ & $\mathrm{n}=12^{\mathrm{b}}$
\end{tabular}

Emergent Vegetation Samples

\begin{tabular}{cccc} 
& Dec 2011 & La Plata $(\mathrm{n}=7)$ & \\
E & Jan 2012 & Arrecifes $(\mathrm{n}=5)$ & $\mathrm{n}=14^{\mathrm{c}}$ \\
\hline F & Larch 2012 & Arrecifes $(\mathrm{n}=6)$ & \\
& & \\
\hline
\end{tabular}

${ }^{a} 10$ sites with values averaged over two dates (Groups A and B), four sites sampled only once during 2011-2012.

${ }^{\mathrm{b}} 12$ sites with values averaged over two dates (Groups C and D)

${ }^{\mathrm{c}} 11$ sites with values averaged over two dates (Groups E and F), three sites sampled only once

\section{Physico-chemico, habitat and geographical variables}


At each sampling site, $\mathrm{pH}$, conductivity, dissolved oxygen, and temperature were measured with a Yellow Springs Instruments SI 556 multi-parameter probe (Yellow Springs, OH, USA). During 2013 - 2014, turbidity was measured with a portable turbidity meter (Hanna Instruments 93414, Woonsocket, RI, USA). Sediment samples were collected for sediment grain size analysis, and organic carbon analysis by ferrous sulfate titration (USDA 1996) (Table S2).

Water samples for analysis of nutrients and major ions were collected in 11 polyethylene bottles and kept in coolers with ice until analyzing or freezing within 24 hours of collection. Water samples were filtered (Whatman GF/C) and suspended solids were measured based on weight of filtered material. Dissolved nutrient and major ion concentrations were determined in the filtered water (APHA 2005). Soluble reactive phosphorus was determined by colorimetry through reaction with molybdate-ascorbic acid; nitrite and nitrate by hydrazine reduction followed by diazotization; and ammonium by the reaction of indophenol blue (APHA 2005). Calcium and magnesium were determined by atomic absorption, sodium and potassium by photometry, bicarbonates by Gran titration, sulfates by turbidimetry, and chlorides by silver nitrate titration (APHA 2005).

At each site visit, maximum stream width and depth were measured. Catchments for each site were delineated in geographical information systems (GIS) using topographical layers, and catchment areas were calculated. Elevation and stream gradient immediately upstream of each site was estimated based on topographical contours (Table S2). At the Arrecifes sites sampled during 2013 - 2014, stream velocity was measured and approximate percent area coverage of emergent, submerged, and floating vegetation was estimated (Table S2), but no quantitative data 
on these parameters were collected at either the La Plata or Arrecifes sampling sites in 20112012

\section{Sediment sample collection and insecticide analysis}

The methods for sediment sample collection and analysis of insecticides have been previously described (Hunt et al., 2016). Briefly, composite sediment samples collected from the first $2 \mathrm{~cm}$ of sediment layer were prepared from three to five locations within a $50 \mathrm{~m}$ reach at each site, and insecticides were extracted from sediments by sonication (You et al. 2008). Samples collected in 2011-2012 were analyzed for cypermethrin, lambda-cyhalothrin, endosulfan, and chlorpyrifos by gas chromatography-electron capture detection (GC-ECD) with a quantification limit of $0.5 \mathrm{ng} / \mathrm{g}$ dry weight. Samples collected in 2013-2014 were analyzed for the same insecticides plus additional pyrethroid and organochlorine insecticides using gas chromatography - mass spectrometry - negative chemical ionization (GC-MS-NCI) with a quantification limit of 0.25 ng/g dry weight.

\section{Toxic unit calculation}

Insecticide toxic units (TUs) were calculated for all sediment samples:

$$
\mathrm{TU}=\mathrm{C}_{i} / \mathrm{EC} 0_{i}
$$

where $\mathrm{C}_{i}$ was the insecticide concentration in sediment normalized for total organic carbon (TOC), and $\mathrm{EC} 50_{i}$ was the 10-d median effects concentration for mortality or immobilization for each insecticide. 
The sediment LC50 values for freshwater aquatic invertebrates were identified for sensitive species (Table 2). Most of the LC50 values used in the present study were for the amphipod Hyalella azteca, which is known to be very sensitive to pyrethroids and chlorpyrifos (Weston and Lydy 2010). Although H. azteca does not occur in Argentina, several closely related species (e.g. H. curvispina, H. pampeana, and H.pseudoazteca) are important components of the aquatic invertebrate communities in the Pampas, and the pesticide sensitivity of $H$. curvispina has been shown to be similar to that of H. azteca (Mugni et al., 2013; Hunt, unpublished data). For endosulfan, Chironomus tentans was more sensitive than H. azteca (You et al., 2004); accordingly, the LC50 for $C$. tentans was used to calculate the TU. Toxicity of pesticides in sediment is highly dependent on organic carbon content; therefore, the concentrations were normalized for total organic carbon to calculate TU values.

The TU values for all insecticides were summed to calculate total insecticide TUs, and TU values for all pyrethroid insecticides were used to calculate total pyrethroid TUs. When summing TU values, all insecticides that were detected in the data set were included, assigning a concentration of half the quantification limit for pesticides that were not detected in the sample, or that were detected below the reporting limit. This approach was used because many of the insecticides were frequently detected below the reporting limit; thus, it was known that they were present, but could not be accurately quantified (Hunt et al., 2016). The data sets for each sampling event were not an adequate size to use a statistical approach, such as maximum likelihood estimate, to estimate values of concentrations below the quantification limit (Helsel, 2012). While this approach may overestimate total TU values in some samples, in most cases the insecticides not detected in a sample did not contribute more than $1 \%$ of the total TU value. 
Insecticides that were measured but not detected in a given sampling event were not included in TU calculations for that sampling event.

\section{Macroinvertebrate collection and identification}

Benthic macroinvertebrate samples were collected by dragging a $30 \mathrm{~cm}$ D-frame dip net with $500 \mu \mathrm{m}$ mesh (Wildco, Yulee, FL, USA) over the bottom sediment of each $1 \mathrm{~m}$ transect. Because of high variability in the number of organisms obtained, sample size was adapted over time to ensure a sufficient number of organisms in each sample (Table 1). In 2011-2013, all

invertebrates from the entire composite sample (five transects, or approximately $1.5 \mathrm{~m}^{2}$ in 2011 2012, and nine transects, or approximately $2.7 \mathrm{~m}^{2}$ in 2013) were sorted and identified. In 2014, a subsampling method was used. A sample of approximately $2.7 \mathrm{~m}^{2}$ was obtained at each site, and the sample material was homogenized and divided into 24 quadrats. Organisms from randomly selected quadrats were sorted until a total count of 500 organisms per sample was reached, or until organisms from all quadrats were sorted. This is close to the upper range of counts used in US biomonitoring programs involving fixed-numbers of organisms (Carter and Resh, 2013). Once initiating the sorting of a quadrat, it was finished to completion even if the target of 500 organisms was reached before finishing the quadrat. Sampled area was estimated based on the proportion of the sample counted, and abundance was normalized for the sampled area.

Macroinvertebrate communities associated with emergent vegetation were sampled only during 2011-2012, and only at sites with sufficient emergent vegetation. Five $1 \mathrm{~m}$ vegetation transects were swept with a $30 \mathrm{~cm}$ D-frame dip net (net opening area of approximately $600 \mathrm{~cm}^{2}$ ) with 500 
$\mu \mathrm{m}$ mesh (Wildco, Yulee, FL, USA), for a total sample area of approximately $1.5 \mathrm{~m}^{2}$. All invertebrates from the entire composite sample were sorted and identified.

All samples were preserved in the field in $80 \%$ ethanol, later sieved $(500 \mu \mathrm{m})$ in the laboratory, sorted under $3 \mathrm{X}$ magnification, and identified under a stereoscopic microscope. Insects, hydroids, decapods, and amphipods were generally identified to family or lower level, and other taxa were identified by higher taxonomic groups (oligochaetes, nemerteans, turbellarians, leeches, nematodes, gastropods, bivalves, isopods, ostracods) using keys from Dominguez and Fernandez (2009) and Merritt and Cummins (2008).

\section{SPEAR index and optimization of sensitivity thresholds}

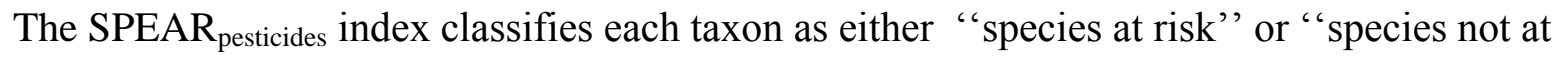
risk" based on four biological traits: (1) physiological sensitivity to organics compounds; (2) generation time; (3) pesticide exposure potential; and, (4) migration ability (Liess and Ohe, 2005).

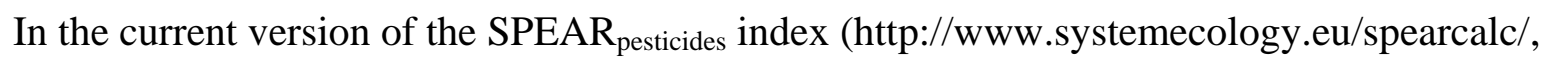
Version 0.9 .0 ), binary values are assigned for each trait as follows: (1) physiological sensitivity of 1 for taxa with relative sensitivity > threshold, otherwise 0 ; (2) generation time sensitivity of 1 for taxa with generation time $\geq$ threshold, otherwise 0 ; (3) exposure sensitivity of 1 for epibenthic taxa, or 0 for sediment-dwelling taxa; and, (4) migration sensitivity of 0 for organisms with documented ability to migrate rapidly, 1 for all others. A taxon is defined as "species at risk', only if values for all four traits are equal to 1. 


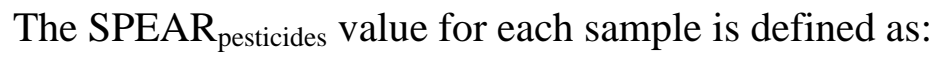

$$
\text { SPEAR }_{\text {pesticides }}=\frac{\sum_{i=1}^{n} \log \left(x_{i}+1\right) \cdot y}{\sum_{i=1}^{n} \log \left(x_{i}+1\right)} \cdot 100
$$

where $n$ is the number of taxa, $x_{i}$ is the abundance of the taxon $i$ and $y$ is 1 if taxon $i$ is classified as "species at risk", otherwise 0.

Generation times for each taxon in the established SPEAR database had been previously identified for European taxa (http://www.systemecology.eu/spearcalc/index.en.html) and Australian taxa (Schäfer et al., 2011a). It is likely that generation times of similar multivoltine taxa in the Pampas are shorter than in most temperate zones because they can reproduce during most of the year. Although reproduction of some taxa in Pampas streams may be reduced during some periods of the year, sufficient data do not exist to identify generation times of local taxa. In addition, the invertebrate community composition of Pampas streams may be different than

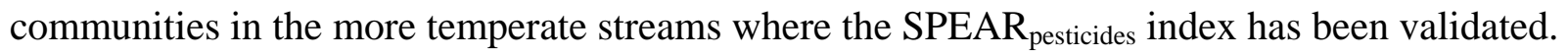
Because the climate of the Argentine Pampas is more similar to that of Australia than that of Europe, and because taxa from South America and Australia may have shared genetic origins, it may be more appropriate to use trait data for Australian taxa than for European taxa, in the absence of sufficient Argentina taxa trait data. For the present study, we conducted the SPEAR analysis using generation time values for Australian taxa when available (Schäfer et al., 2011a), supplemented by generation time values reported for European taxa 
(http://www.systemecology.eu/spearcalc/index.en.html) for taxa that had no data available in the Australian database.

In the present study, we used an optimization approach to adjust the pesticide sensitivity and generation time thresholds using Argentine Pampas data sets. The default threshold value for generation time is $0.5 \mathrm{yr}$ (a taxon must have a generation time of at least $0.5 \mathrm{yr}$ to be considered

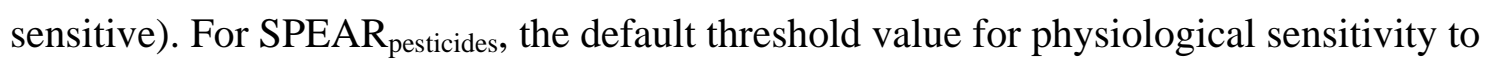
pesticides is -0.36 (a taxon must have a relative sensitivity score greater than -0.36 to be considered sensitive). The relative sensitivity score for each taxon for a given pesticide is calculated as the mean of the ratios of all reported LC50 values for the taxon divided by the mean Daphnia magna LC50 value. The overall pesticide relative sensitivity score for each taxon is calculated as the mean relative sensitivity value for all pesticides included (Von der Ohe and Liess, 2004). For the present study we used the most recent relative sensitivity scores based on globally reported data for all taxa within each family (http://www.systemecology.eu/spearcalc/index.en.html). The default sensitivity threshold value used for the SPEAR index (-0.36) was set so that approximately one half of the taxa were designated as sensitive and one half as insensitive. As invertebrate community composition is likely to change based on region and habitat conditions, these threshold values can be adjusted based on local invertebrate communities.

Although some taxa in the present study were identified to genus or species level, in many samples they could not consistently be identified to a level lower than family. Therefore we used

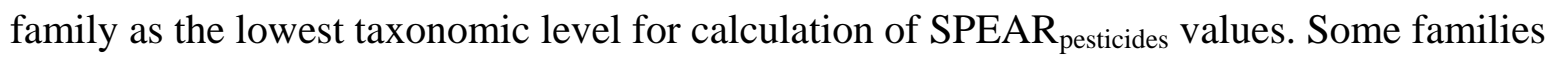


found in the present study were not included in the existing SPEAR databases for European and Australian taxa, and for these missing families we assigned the trait values available for higher taxonomic levels (Table S3).

For each data group A to E (Table 1), we simultaneously optimized the values for the pesticide sensitivity and generation time thresholds to achieve maximum inverse correlation between SPEAR values and log-transformed TU values. Global optimization was performed with the differential evolution algorithm, using the DEoptim package in R (Mullen et al., 2011). To avoid overfitting to data sets with small sample size, optimum threshold values calculated for each of the four benthic invertebrate sample groups (A-D) were averaged to obtain final threshold values applied to all benthic and vegetation-associated invertebrate samples. It is reasonable to expect that the optimum threshold values may be different for vegetation-associated communities than for benthic communities, but there were too few vegetation-associated invertebrate samples to perform optimization without high potential for overfitting.

The default SPEAR exposure potential values are based on exposure in the water column because the SPEAR pesticides index has mostly been related to pesticide concentrations in water. However, insecticides in the present study were measured in sediment, because these insecticides are hydrophobic and more likely to be adsorbed to sediments than to be dissolved in water. Therefore, insecticide exposure to both epibenthic and sediment dwelling organisms is likely to be high. Consequently, as part of the $\mathrm{SPEAR}_{\text {pesticides }}$ optimization process, we compared the results using default taxa exposure values, and exposure values of 1 (exposed) for all epibenthic and sediment-dwelling taxa. 


\section{Additional bioassessment metrics}

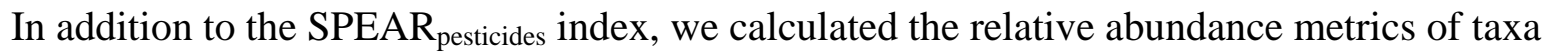
groups that were selected based on their high abundance in the region (Table S3), and/or known high sensitivity or tolerance to pesticides and other pollutants (Table 3) (Chang et al., 2014; Rubach et al., 2010). We also calculated the Shannon diversity index and taxa richness. Samples containing more than 300 organisms were rarefied to a constant size of 300 organisms to reduce the effect of sample size (Barbour and Gerritsen, 1996).

\section{Regression analysis}

We performed regression analysis on three data sets, each of which contained variable values that were averaged over two sampling events (Table 1). For benthic invertebrate samples, we used average values for the two events in 2011-2012, and for the two events in 2013-2014. For vegetation-associated invertebrate samples, we used average values for the two events in 20112012.

First, we calculated univariate linear regression relationships ( $\mathrm{lm}$ function in $\mathrm{R}$ version 3.2.2) between insecticide TU values (log transformed) and all response metrics (Table 3). For metrics that were significantly correlated with log TU values, we then performed multiple linear regression to evaluate the relative importance of insecticides and other variables in determining variance in each response metric. 
At each site we had measured values for many water quality, habitat, and watershed characteristics (Table S2), many of which were highly correlated. Given the sample size of each data set, we had to limit the number of predictor variables to include only those most likely to independently effect the response variables. We did not include parameters that did not vary much between sites, or ones that had missing values for some sites. To avoid predictor variables with high collinearity and interdependence, we first used a correlation matrix (Table S4) to select variables that were highly correlated with response variables, but not with other predictor variables. For each data set, we selected one parameter from each parameter group type (e.g. nutrients, salinity, stream size, and habitat). After initial variable selection, we checked variance inflation factors (VIFs) with the full model to avoid high collinearity ("vif" function in R package "cor") to confirm that all VIFs for all variables were $<3$.

We then selected the best predictive models based on Akaike information criterion values corrected for small sample size (AICc) and p-values. The $\triangle \mathrm{AICc}$ for each model was calculated as the difference between the AICc for the model and the lowest AICc of all models. For each predictor variable in selected models with $\triangle \mathrm{AICc}<4$ and $\mathrm{p}$-value $<0.05$, we determined the magnitude and direction of coefficients using multi-model averaging across selected models (Grueber et al., 2011) using the dredge and model.avg functions in the R package MuMIn version 1.15.1 (Barton, 2015), using partial standard deviations of predictor variables to standardize for differences in scales resulting from multicollinearity (Cade, 2015). Relative importance was calculated as the model-averaged ratios of absolute values of standardized coefficients based on the AIC model weights (Cade, 2015). These ratios are scaled relative to a maximum of 1.0 for the strongest predictor within each model. Importance ranges from 0 
(parameter not given any explanatory weight in any of the selected models) to 1 (parameter included and assigned highest relative importance in all selected models).

\section{Results}

\section{Insecticide TU values}

The most commonly detected insecticides were those that are reported to be the most heavily used in soy production in Argentina: chlorpyrifos, endosulfan (and its degradation product endosulfan sulfate), cypermethrin, and lambda-cyhalothrin (Table 2). Bifenthrin and organochlorine insecticides were detected only occasionally.

Insecticide detection patterns varied between the two regions. In the mixed agriculture region of La Plata, the maximum total insecticide TU values for the 2011 and 2012 sampling events were 0.66 and 0.14 (based on C. tentans and H. azteca), and chlorpyrifos was the only insecticide that was consistently detected. In the intensive soy production region of Arrecifes, maximum total insecticide TU values for the four sampling events ranged from 0.51 to 1.36 , and multiple insecticides were detected at most locations (Table 2). In Arrecifes, pyrethroid (cypermethrin and lambda-cyhalothrin) concentrations were the primary contributors to high TU values, while in La Plata endosulfan was the primary contributor. 
Table 2. Detection frequencies and maximum toxic units (TUs) for each sampling event, for insecticides that had at least one TU value $>0.01$. TUs were calculated as the ratio of the carbon-normalized concentration in sediment over the carbon-normalized LC50. Insecticide concentrations were reported in Hunt et al. (2016).

\begin{tabular}{|c|c|c|c|c|c|c|c|c|}
\hline \multirow[b]{2}{*}{ Pesticide } & \multirow{3}{*}{$\begin{array}{c}\text { LC50 (ng/g } \\
\text { organic }\end{array}$} & \multirow[b]{2}{*}{ Statistic } & \multicolumn{2}{|c|}{ La Plata } & \multicolumn{4}{|c|}{ Arrecifes } \\
\hline & & & Dec & Mar & Jan & Mar & Feb & Feb \\
\hline & & & 2011 & 2012 & 2012 & 2012 & 2013 & 2014 \\
\hline & carbon) & & & & & & & \\
\hline \multirow[t]{2}{*}{ Chlorpyrifos } & $4160^{\mathrm{a}}$ & Max TU & 0.01 & 0.02 & 0.06 & 0.16 & 0.09 & 0.08 \\
\hline & & Frequency $^{\mathrm{b}}$ & $29 \%$ & $57 \%$ & $86 \%$ & $100 \%$ & $100 \%$ & $67 \%$ \\
\hline \multirow[t]{2}{*}{ Endosulfan } & $960^{c}$ & Max TU & 0.32 & 0.04 & 0.14 & 0.18 & 0.01 & 0.09 \\
\hline & & Frequency $^{\mathrm{b}}$ & $29 \%$ & $14 \%$ & $57 \%$ & $43 \%$ & $8 \%$ & $17 \%$ \\
\hline \multirow[t]{2}{*}{ End. sulfate } & $5220^{c}$ & Max TU & 0.28 & 0.07 & 0.08 & 0.10 & 0.12 & 0.03 \\
\hline & & Frequency $^{\mathrm{b}}$ & $29 \%$ & $14 \%$ & $29 \%$ & $57 \%$ & $58 \%$ & $33 \%$ \\
\hline \multirow[t]{2}{*}{ Cypermethrin } & $380^{\mathrm{a}}$ & Max TU & 0.05 & nd & 1.15 & 0.97 & 0.38 & 0.13 \\
\hline & & Frequency $^{\mathrm{b}}$ & $29 \%$ & $0 \%$ & $29 \%$ & $29 \%$ & $33 \%$ & $8 \%$ \\
\hline \multirow[t]{2}{*}{ L-cyhalothrin } & $450^{\mathrm{a}}$ & Max TU & NA & 0.02 & NA & 0.71 & 0.23 & 0.16 \\
\hline & & Frequency $^{\mathrm{b}}$ & & $0 \%$ & & $29 \%$ & $17 \%$ & $0 \%$ \\
\hline \multirow[t]{2}{*}{ Bifenthrin } & $520^{\mathrm{d}}$ & Max TU & NA & NA & NA & NA & nd & 0.36 \\
\hline & & Frequency $^{\mathrm{b}}$ & & & & & $0 \%$ & $17 \%$ \\
\hline \multicolumn{2}{|c|}{ Total pyrethroid TU $\mathrm{e}^{\mathrm{e}, \mathrm{g}}$} & Mean TU & 0.05 & 0.05 & 1.15 & 1.16 & 0.45 & 0.41 \\
\hline
\end{tabular}




$\begin{array}{llllllll}\text { Total insecticide } \mathrm{TU}^{\mathrm{f}, \mathrm{g}} & \text { Max TU } & 0.66 & 0.14 & 1.23 & 1.36 & 0.51 & 0.54\end{array}$

${ }^{\mathrm{a}}$ LC50 for Hyalella azteca from Weston et al. (2013)

${ }^{\mathrm{b}}$ Frequency of detection above the highest quantitation limit of $0.5 \mathrm{ng} / \mathrm{g} \mathrm{dw}$ in sediment.

${ }^{\mathrm{c}}$ LC50 for Chironomus tentans from You et al. (2005)

${ }^{\mathrm{d}}$ Frequency of detection above the highest quantitation limit of $0.25 \mathrm{ng} / \mathrm{g} \mathrm{dw}$ in sediment

e Total pyrethroid TU values for each sample were calculated by summing the TU values for each pyrethroid.

${ }^{\mathrm{f}}$ Total insecticide TU values for each sample were calculated by summing the TU values for each insecticide.

${ }^{\mathrm{g}} \mathrm{A}$ concentration value of half the quantitation limit was assigned for pesticides detected in the sample group, but not detected in the sample, or detected $<\mathrm{QL}$ in the sample.

\section{SPEAR $\boldsymbol{R}_{\text {pesticides }}$ threshold optimization}

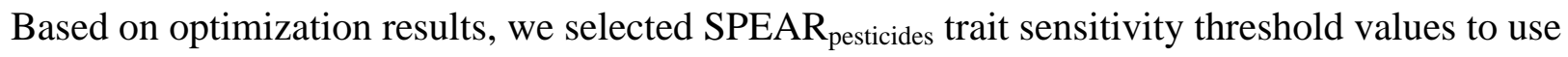
for the regression analysis. The pesticide sensitivity threshold was optimized at a range between -0.24 and 0.06 , and we arbitrarily selected a value of -0.2 as there is no difference in results as long as the selected value is within the optimized range. Similarly, the generation time threshold was optimized at a range between 0 and 0.5 year, and we selected a value of 0.5 because this is

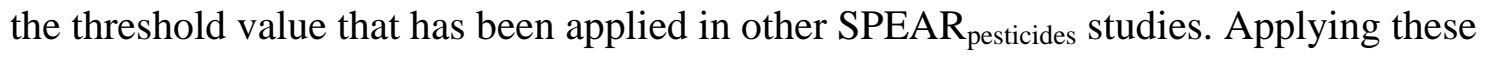
threshold values, the only taxa that were considered sensitive with respect to all four traits (overall SPEAR $\mathrm{R}_{\text {pesticides }}$ score of one) were the trichopteran family Hydroptilidae, and all Crustacea taxa (Hyalellidae, Palaemonidae, Aeglidae, Caridae, Ostracoda). For most data sets, 
slightly better correlations were achieved when exposure values for all taxa (both epibenthic and sediment dwelling) were set equal to 1 (sensitive with respect to exposure), so we set exposure values equal to 1 for all taxa. 


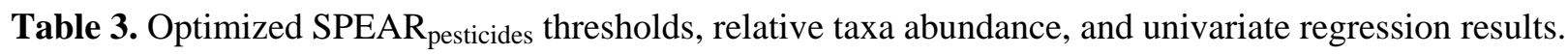

Univariate Regression Results

\begin{tabular}{lccccccc}
\cline { 2 - 4 } & Desponse Variable & Total Insecticide TU & \multicolumn{3}{c}{ Pyrethroid TU } \\
& Group & Trend $^{\mathrm{a}}$ & $\mathrm{r}^{2}$ & $\mathrm{p}$-value & Trend $^{\mathrm{a}}$ & $\mathrm{r}^{2}$ & $\mathrm{p}$-value
\end{tabular}

Benthic invertebrate communities

Optimized SPEAR Thresholds

Sensitivity

Generation

Time (yr)

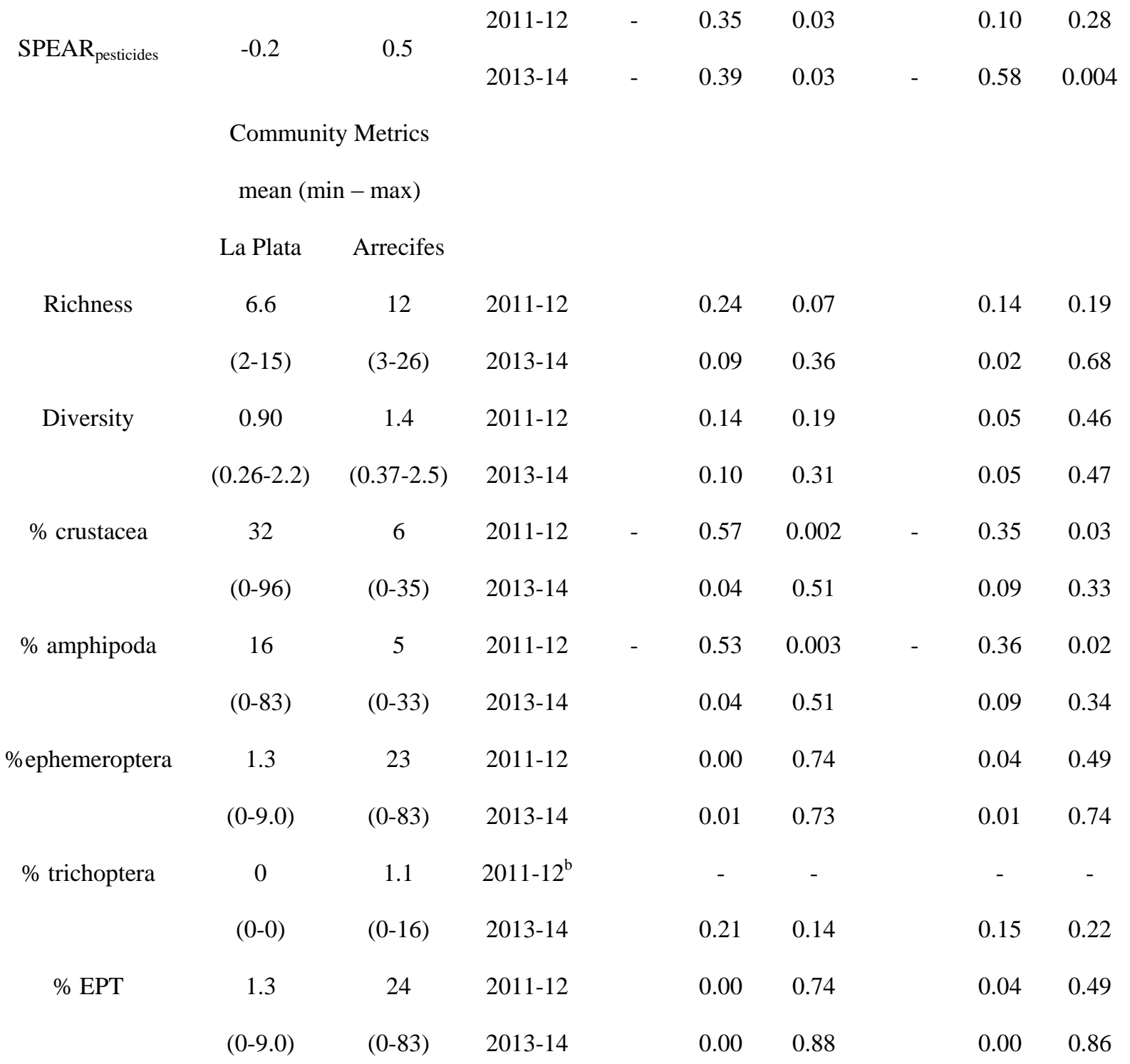




\begin{tabular}{|c|c|c|c|c|c|c|c|c|}
\hline \multirow[t]{2}{*}{$\%$ diptera } & 3.1 & 20 & 2011-12 & 0.20 & 0.11 & & 0.25 & 0.07 \\
\hline & $(0-15)$ & $(0-89)$ & 2013-14 & 0.00 & 0.99 & & 0.00 & 0.97 \\
\hline \multirow[t]{2}{*}{$\%$ chironomidae } & 2.6 & 19 & 2011-12 & 0.22 & 0.09 & & 0.27 & 0.06 \\
\hline & $(0-15)$ & $(0-83)$ & 2013-14 & 0.00 & 0.99 & & 0.00 & 0.95 \\
\hline \multirow[t]{2}{*}{$\%$ oligochaetes } & 40 & 16 & 2011-12 & 0.20 & 0.11 & & 0.01 & 0.70 \\
\hline & $(0-91)$ & $(0-83)$ & 2013-14 & 0.00 & 0.87 & & 0.02 & 0.70 \\
\hline \multirow[t]{2}{*}{$\%$ bivalvia } & 2 & 4 & 2011-12 & 0.08 & 0.32 & & 0.05 & 0.46 \\
\hline & $(0-12)$ & $(0-38)$ & 2013-14 & 0.32 & 0.05 & - & 0.47 & 0.01 \\
\hline \multirow[t]{2}{*}{$\%$ gastropoda } & 4 & 16 & 2011-12 & 0.01 & 0.78 & & 0.04 & 0.49 \\
\hline & $(0-17)$ & $(0-89)$ & 2013-14 & 0.01 & 0.72 & & 0.04 & 0.54 \\
\hline
\end{tabular}

Vegetation-associated invertebrate communities

\begin{tabular}{|c|c|c|c|c|c|c|c|c|}
\hline \multicolumn{9}{|c|}{ Optimized SPEAR Thresholds ${ }^{c}$} \\
\hline & \multirow{2}{*}{ Sensitivity } & \multicolumn{7}{|l|}{ Generation } \\
\hline & & \multicolumn{7}{|l|}{ Time $(y r)$} \\
\hline \multirow[t]{4}{*}{ SPEAR $_{\text {pesticides }}$} & -0.2 & 0.5 & 2011-12 & - & 0.42 & 0.01 & 0.14 & 0.19 \\
\hline & \multicolumn{8}{|c|}{ Community Metrics } \\
\hline & \multicolumn{8}{|c|}{ mean $(\min -\max )$} \\
\hline & La Plata & Arrecifes & & & & & & \\
\hline Richness & $13(4.3-25)$ & $18(5.3-30)$ & 2011-12 & & 0.05 & 0.42 & 0.09 & 0.28 \\
\hline \multirow[t]{2}{*}{ Diversity } & $14(0220$ & $1.7(0.8-$ & 2011-12 & & 0.17 & 0.14 & 0.15 & 0.17 \\
\hline & & 2.9) & & & & & & \\
\hline$\%$ crustaceans & $41(0-94)$ & $25(0.1-68)$ & 2011-12 & - & 0.34 & 0.03 & 0.07 & 0.37 \\
\hline$\%$ amphipods & $40(0-94)$ & $23(0.1-67)$ & 2011-12 & - & 0.29 & 0.04 & 0.06 & 0.39 \\
\hline \%ephemeroptera & $0.7(0-3.1)$ & $19(0-70)$ & 2011-12 & & 0.2 & 0.60 & 0.03 & 0.56 \\
\hline$\%$ trichoptera & $0.2(0-2.1)$ & $0.1(0-0.8)$ & 2011-12 & & 0.02 & 0.62 & 0.00 & 0.82 \\
\hline
\end{tabular}




$\begin{array}{lccccccc}\text { \% EPT } & 0.9(0-5.2) & 19(0-71) & 2011-12 & 0.02 & 0.60 & 0.03 & 0.57 \\ \text { \% diptera } & 4.7(0-42) & 12(0.3-34) & 2011-12 & 0.03 & 0.56 & 0.07 & 0.37 \\ \text { \% chironomids } & 1.3(0-5.5) & 7.9(0.2-23) & 2011-12 & 0.11 & 0.25 & 0.13 & 0.21 \\ \text { \% oligochaetes } & 14(0-71) & 16(0-63) & 2011-12 & 0.18 & 0.13 & 0.05 & 0.46 \\ \text { \% bivalvia } & 0.1(0-0.7) & 0.1(0-0.7) & 2011-12 & 0.02 & 0.62 & 0.00 & 0.82 \\ \text { \% gastropoda } & 6.5(0-36) & 5.9(0-34) & 2011-12 & 0.17 & 0.13 & 0.00 & 0.79\end{array}$

a “+” signifies positive significant correlation, “-” signifies negative significant correlation

\footnotetext{
${ }^{\mathrm{b}}$ No trichoptera were present in benthic samples collected in 2011-2012.

${ }^{\mathrm{c}}$ Thresholds optimized for benthic samples were applied to vegetation samples, because too few vegetation data sets were available to optimize thresholds.
}

\section{Univariate linear regressions}

SPEAR $_{\text {pesticides }}$ was the metric that performed most consistently well in predicting invertebrate community response to insecticides. SPEAR pesticides $\%$ crustaceans, and $\%$ amphipods were the only response metrics that were significantly correlated with insecticide TUs for more than one data group (Table 3). The only other community metric that exhibited a significant correlation with TU was \% bivalvia, which was inversely correlated with pyrethroid TU only for the 20132014 benthos data group. SPEAR pesticides $_{\text {was }}$ the only response metric that was significantly correlated with total insecticide TU values for all three averaged data sets, consistently showing a trend of decreasing values with increasing TU values $\left(\mathrm{r}^{2}=0.35\right.$ to 0.42 , $\mathrm{p}$-value $=0.001$ to 0.03) (Table 3; Figure 3). Percent crustaceans and \% amphipods were significantly correlated with total insecticide TU values in two of the three data groups. The relative abundance of both 
crustaceans and amphipods were highly correlated for all data sets $\left(0.39<r^{2}<0.98\right.$; p-value $<0.018$ ), and the two metrics performed very similarly (Table 3).

Total insecticide TU was usually a better predictor than pyrethroid TU for the three most responsive metrics $\left(\mathrm{SPEAR}_{\text {pesticides}}, \%\right.$ crustaceans, and \% amphipods), with the exception of the 2013-2014 benthos data group. Although significant correlations were obtained between pyrethroid TU and some predictor variables $\left(\mathrm{SPEAR}_{\text {pesticides, }} \%\right.$ crustaceans and \% amphipods), the correlations were weaker than those for total insecticide TU. 
(a) SPEAR - Vegetation 2011-2012

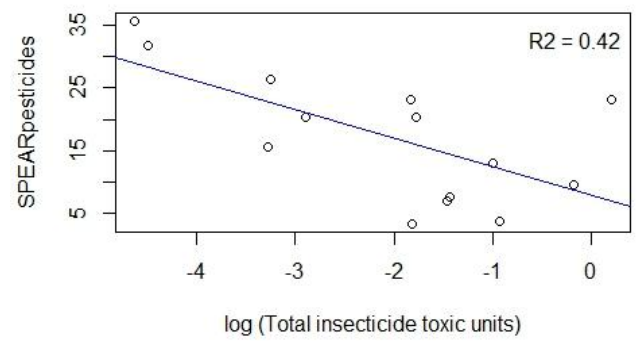

(b) SPEAR - benthos 2011-2012

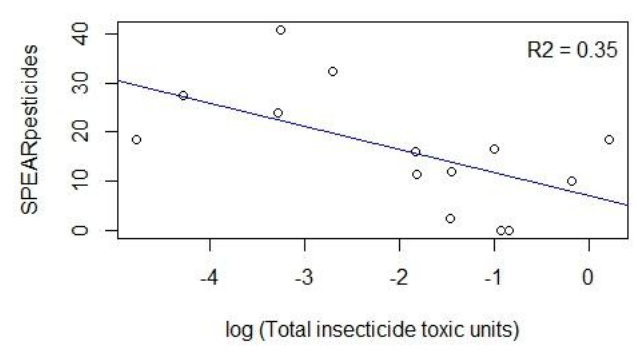

(c) SPEAR - benthos 2013-2014

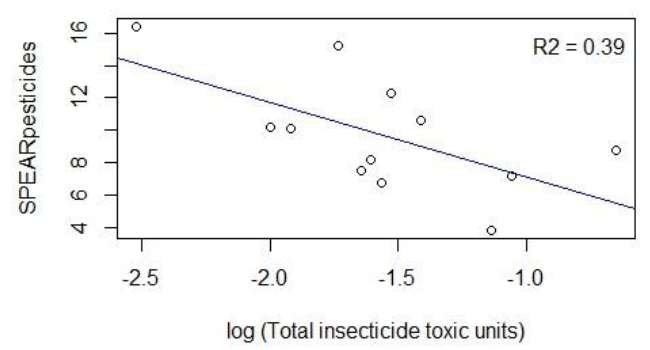

(d) Crustacea - vegetation 2011-2012

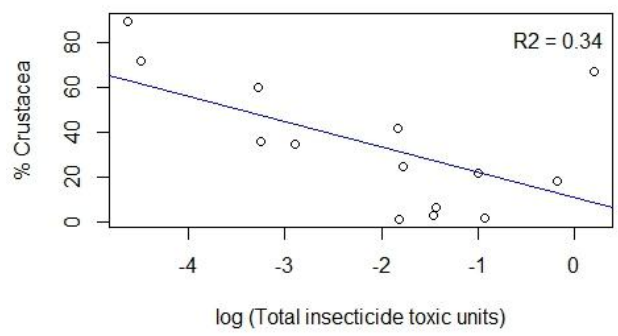

(e) Crustacea - benthos 2011-2012

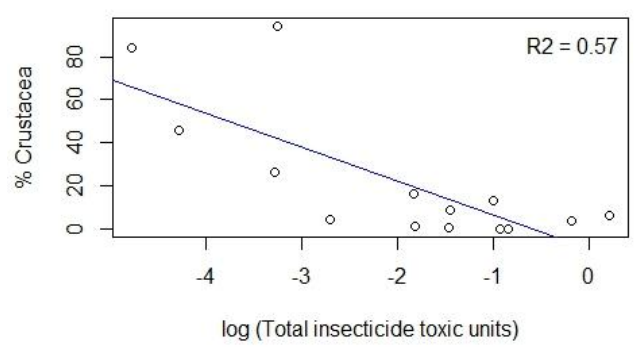

(f) Crustacea - benthos 2013-2014

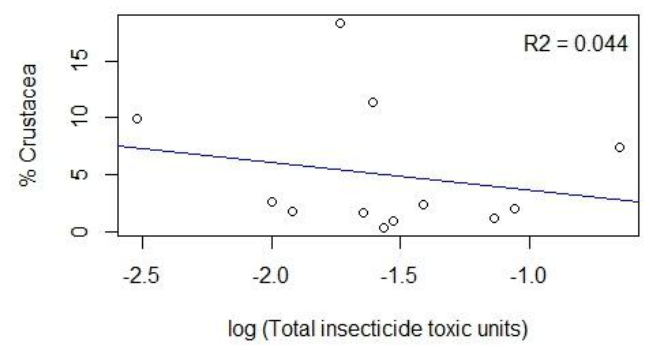

Figure 3. Univariate linear regression between total insecticide TUs and community metrics for (a)

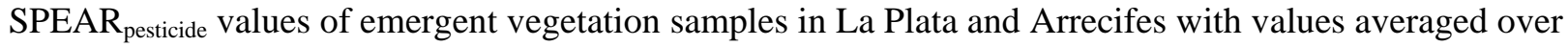

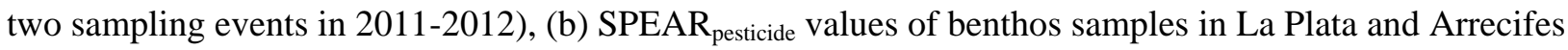
with values averaged over two sampling events in 2011-2012, (c) benthos samples in Arrecifes with 
values averaged over two sampling events in 2013-2014, (d) \% crustacea values of emergent vegetation samples in La Plata and Arrecifes with values averaged over two sampling events in 2011-2012), (e) \% crustacea values of benthos samples in La Plata and Arrecifes with values averaged over two sampling events in 2011-2012, and (f) \% crustacea of benthos samples in Arrecifes with values averaged over two sampling events in 2013-2014.

\section{Relative importance of predictor variables}

Based on univariate results, two response metrics $\left(\mathrm{SPEAR}_{\text {pesticides }}\right.$ and \% crustacea) were selected for multivariate linear regression to determine the relative importance of insecticide TU and nonpesticide parameters. Amphipods were not included as a separate response metric in this analysis because their response is very similar to that of total crustacea (Table 3).

For all data sets, total insecticide TU was the most important variable in explaining variance in

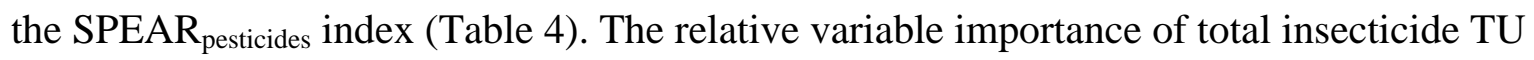
ranged from 0.85 to 1.00 for the three data groups. Relative importance of non-pesticide predictor variables used in models that included total insecticide TU ranged from 0.06 to 0.28 .

Chloride was important in explaining variability in relative abundance of crustaceans, but less so

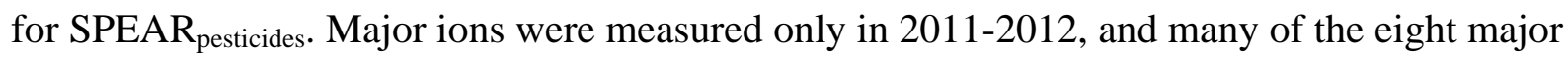
ions were found to be collinear with each other, with conductivity, and with TU values. To avoid redundancy, chloride was the only ion selected as a predictor variable in the full models for 2011-2012, because it had low negative correlation with TUs and high correlation with two response metrics $\left(\mathrm{SPEAR}_{\text {pesticides }}\right.$ and \% crustacea). For the 2013-2014 data set, conductivity was selected instead of chloride, because major ions were not measured. Chloride was identified as a 
variable with low to high importance in most of the 2011-2012 averaged models (Table 4). In particular, it had high importance in explaining the variance in \% crustacea (relative importance 0.57-1.00), with relative abundance of crustaceans increasing with chloride concentration. Total conductivity was not found to be important in explaining variance of any response metrics for the 2013-2014 data set. For 2011-2012, the models were also run using conductivity in place of chloride to compare their relative importance, with the importance of conductivity being consistently lower than chloride (not shown).

In some cases nutrient concentrations exhibited low or moderate correlations with the

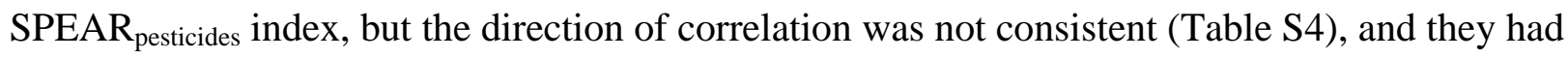
no apparent influence on the relative abundance of crustaceans. Nutrient concentrations were measured during all sampling events, and some nutrients were collinear (Table S4). Most were also positively correlated with TU values, but not with response metrics. Soluble reactive phosporous (SRP) was selected as a predictor variable in the full models, because it had low correlation with TUs. SRP was identified as a variable with low to moderate importance in the SPEAR $_{\text {pesticides }}$ models, but had no importance in explaining variance in \% crustacea (Table 4).

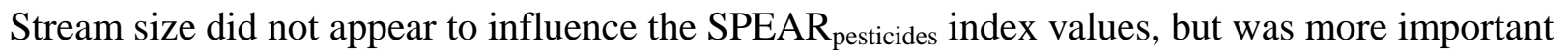
in explaining variability in crustacean abundance. Several metrics were available to represent stream size, including width, depth, elevation, gradient, and catchment area. Depth was selected as a predictor variable in the full models, because it was the stream size variable with lowest correlation with TUs. Depth was identified as an important variable for only one data set (20112012 benthos), where it had high importance in explaining \% crustacea (Table 4). 
Percent floating vegetation was the type of vegetation most highly correlated with response metrics, and was included in the full model for 2013-2014 but was not found to be an important predictor for any metric. Vegetation was not included in the 2011-2012 models because no quantitative data were collected.

Table 4. Averaged model results and relative importance of predictor variables. The symbol “.” indicates no significant correlation.

\begin{tabular}{|c|c|c|c|c|c|c|c|c|c|}
\hline \multirow[t]{2}{*}{ Period } & \multirow{2}{*}{$\begin{array}{l}\text { Sampling } \\
\text { Matrix }\end{array}$} & \multirow{2}{*}{$\begin{array}{l}\text { Response } \\
\text { Metrics }\end{array}$} & \multicolumn{3}{|c|}{ Averaged Models } & \multicolumn{4}{|c|}{ Relative Variable Importance } \\
\hline & & & $\operatorname{adj} r^{2}$ & $\mathrm{AICC}$ & $p$-value & Total TU & SRP & Chloride $^{\mathrm{a}}$ & Depth \\
\hline \multirow[t]{7}{*}{ 2011-2012 } & Benthos & SPEAR pesticides & $0.29-0.38$ & $\leq 111.6$ & 0.03 & 1.00 & 0.28 & - & - \\
\hline & & $\%$ Crustacea & 0.80 & $\leq-2.4$ & $\leq 0.0002$ & 0.03 & - & 1.00 & 0.71 \\
\hline & Vegetation & SPEAR pesticides & $0.24-0.38$ & $\leq 107.6$ & $\leq 0.042$ & 0.85 & 0.06 & 0.21 & - \\
\hline & & \% Crustacea & $0.28-0.31$ & $\leq 8.6$ & $\leq 0.0499$ & 0.57 & - & 0.57 & - \\
\hline & & & \multicolumn{3}{|c|}{ Averaged Models } & \multicolumn{4}{|c|}{ Relative Variable Importance } \\
\hline & & & $\operatorname{adj~} r^{2}$ & $\mathrm{AICC}$ & $p$-value & Total TU & SRP & Conducti & Depth \\
\hline & & & & & & & & vity $^{\mathrm{a}}$ & \\
\hline \multirow[t]{2}{*}{ 2013-2014 } & Benthos & SPEAR $_{\text {pesticides }}$ & $0.33-0.40$ & $\leq 68.7$ & & 1.00 & 0.14 & - & - \\
\hline & & $\%$ Crustacea $^{b}$ & - & - & - & - & - & - & - \\
\hline
\end{tabular}

\footnotetext{
${ }^{a}$ Major ions were measured only in 2011-2012, and for this period chloride was found to have higher importance than conductivity in explaining variance in response metrics.

${ }^{\mathrm{b}}$ No models with $\mathrm{p}$-value $<0.5$ were found
} 


\section{Discussion}

The results of the present study demonstrate that insecticide concentrations in streams of the Argentina Pampas are correlated with changes to aquatic invertebrate community composition, and that these changes are not highly influenced by other variables included in the study. To our knowledge, this is the first field study that has demonstrated such effects in soy production regions. In intensive soy production regions in the midwest region of the United States, as well as in Brazil and Argentina, many studies have reported frequent detections of insecticides, as well as toxicity to specific sensitive species (Casara et al., 2012; Di Marzio et al., 2010; Ding et al., 2010; Hladik and Kuivila, 2012; Jergentz et al., 2004a, 2004b; Laabs et al., 2002; Mugni et al., 2011). However, none of these studies investigated effects on entire invertebrate communities over a gradient of pesticide concentrations.

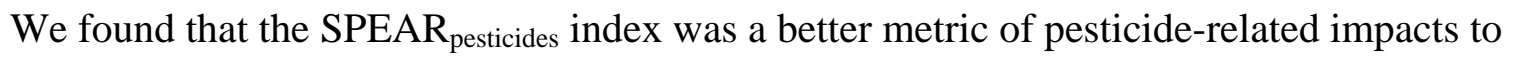
invertebrate communities compared to more general metrics such as taxa richness and diversity, as well as to relative abundance metrics for sensitive invertebrate groups. This is not surprising,

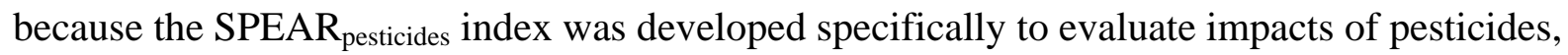
and is based partly on physiological sensitivity to pesticides. Moreover, the ability to

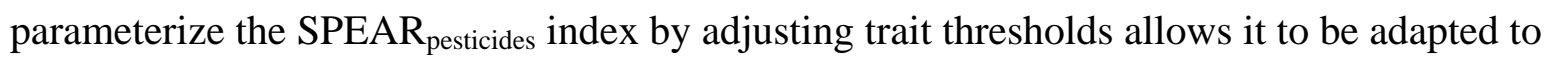
various regions and habitats with different invertebrate community structures. An index such as SPEAR that allows for parameterization is intrinsically expected to perform better than indices that cannot be parameterized (such as relative abundance metrics). Because we averaged the optimized values across several watersheds and over multiple years, we consider the SPEAR 
threshold values to be optimized for streams throughout the Pampas region of Argentina during the summer season. This was confirmed by the strong performance of the SPEAR index for all four combined data sets in our study.

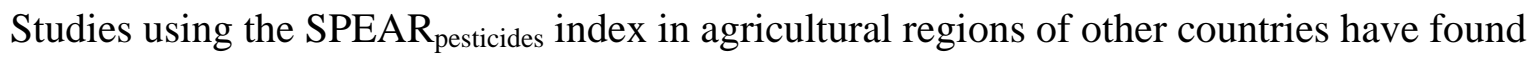
similar results to the present study, usually with stronger correlations (Liess and Von der Ohe, 2005; Münze et al., 2015; Orlinskiy et al., 2015; Schäfer et al., 2012, 2011b, 2007). Schäfer et al. (2012) reported that eight studies in Europe, Siberia and Australia found very good correlations

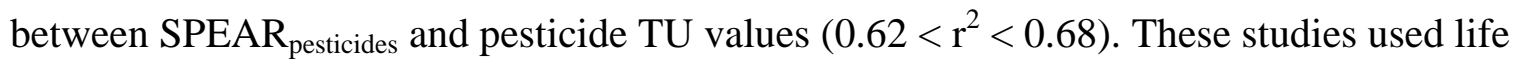
history trait databases based on taxa from the respective regions. In Argentina and in South America in general, such taxa trait data are currently lacking. Although the SPEAR $_{\text {pesticides }}$ index was developed in Europe, it performed well in the Argentine Pampas with only minor modifications, and would likely improve as more data are obtained on the traits of South American taxa such as generation time and migration rates. The SPEAR analysis conducted in the present study was based on a taxonomic resolution of family level or higher, and would likely improve if adequate data were available to conduct the analysis at a lower taxonomic level. Although it has previously been found that the SPEAR index performs similar at family and genus level, this may be primarily the result of a lack of sensitivity data at the genus level (Beketov et al., 2009). Within each family or order, a small number of genera tend to be used as standard test organisms, and relative sensitivity values for these standard test species may not be representative of closely related taxa. This is supported by a recent study that tested sensitivity to pyrthroids in 34 stream invertebrate species, and found that LC50 values could vary by a factor of over 1000 even within the same family (Wiberg-Larsen et al., 2016). The authors of this study 
concluded that certain traits such as smaller body size and preference for course substrate indicated higher pyrethroid sensitivity.

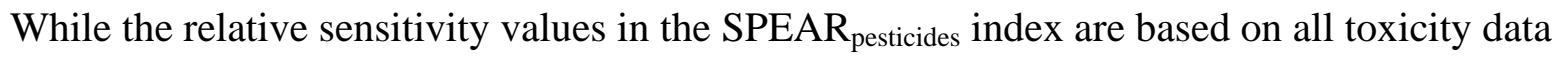
reported globally (Von der Ohe and Liess, 2004), the vast majority of aquatic toxicity tests were performed on species from Europe and North America (Hagen and Douglas, 2014). Kwok et al. (2007) found that tropical species may be more sensitive than temperate species to pesticides, while temperate species are likely to be more sensitive to metals. The lack of biological trait data for local taxa may be one possible contributor to lower performance of the SPEAR pesticides $_{\text {index }}$ in Argentina compared to Europe and Australia, where $\mathrm{r}^{2}$ values typically ranged from about 0.6 to 0.7 (Schäfer et al., 2011b).

Most previous SPEAR studies used lower taxonomic levels than the present study which was based on family level, but it has been demonstrated that the explanatory power of the family level SPEAR pesticides $_{\text {index is not significantly lower than the species level }}$ PEAR $_{\text {pesticides }}$ index (Beketov et al., 2009). Therefore, it is not likely that the taxonomic resolution level is responsible for the somewhat lower correlations found in the Argentine Pampas.

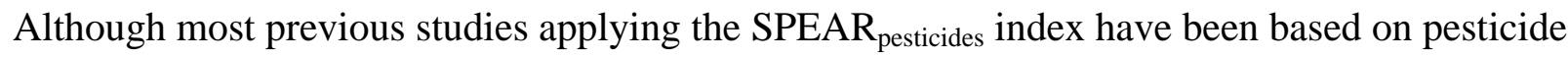
concentrations measured in stream water, Schäfer et. al (2011) found that pesticide concentrations in sediments were more strongly correlated with SPEAR $\mathrm{R}_{\text {pesticides }}$ values in Australian streams. This was surprising given that more compounds and approximately twice the number of total detections above the quantitation limit was found in grab water samples compared to sediment samples. However, the higher detection frequency in water was likely because of more hydrophilic compounds detected in water, and lower quantitation limits in 
analysis of water samples. In addition, the average toxicity of pesticides in water samples was lower than that for sediment samples (Schäfer et al., 2011b). In the present study, the most commonly used insecticides are more likely to partition to sediment than to water, and to remain in sediments at elevated concentrations for at least several weeks after peak water concentrations (Hunt et al., 2016). Therefore, insecticide concentrations in sediment are expected to be a good indicator of invertebrate exposure to insecticides for the present study.

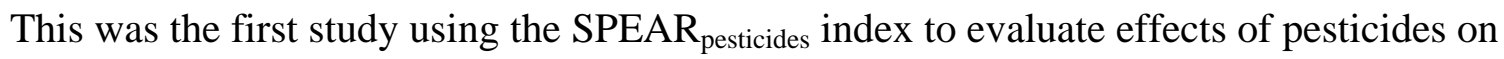
invertebrate samples collected from aquatic vegetation, and its performance was similar to that for benthic invertebrate communities. The data set for vegetation-associated invertebrate communities in the present study was limited, and additional studies would be needed to

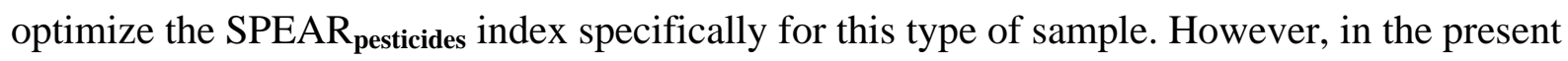
study the taxa composition (relative abundance of major orders) for vegetation-associated communities was similar to that of benthic communities (Table 3), so it is reasonable to expect that the thresholds would be similar for both communities.

The results of the present study are consistent with previous studies that have shown the

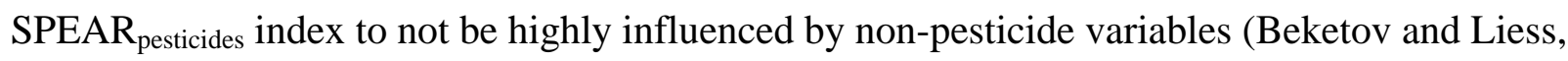
2008; Liess et al., 2008a, 2008b). Beketov and Liess (2008) investigated factors that affect SPEAR $_{\text {organics, }}$ which uses the same taxa relative sensitivity values as SPEAR $_{\text {pesticides, }}$ but does not consider the additional three traits that are included in SPEAR pesticides. $_{\text {. They showed that }}$ SPEAR $_{\text {organics }}$ is independent of stream longitudinal gradient, including factors such as altitude, temperature, stream width, nutrients, and velocity. In contrast, metrics such as EPT richness and Shannon diversity were highly correlated with longitudinal factors (Beketov and Liess, 2008). In 
a study of 24 Australian stream sites, Schäfer et al. (2011b) found that pesticide contamination was the only measured variable explaining variation in $S_{P E A R}$ pesticides, with other measured variables including many water quality, habitat and landscape variables. Although existing studies have not demonstrated a large influence of non-pesticide variables on the SPEAR pesticides index, most of these studies were limited by a small sample size which in turn limited the types of statistical analysis that could be conducted and the number of explanatory variables included. Therefore, parameters that tend to be correlated with pesticide concentrations cannot be ruled out as influencing the SPEAR pesticides $_{\text {index. }}$

Some previous studies did identify specific non-pesticide variables that can affect performance

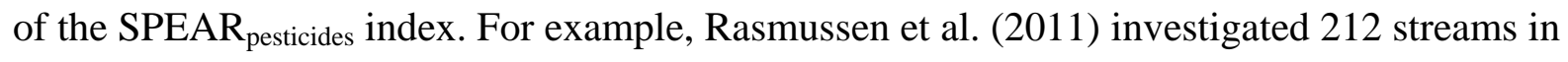

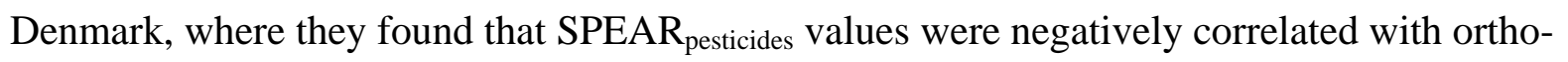
phosphate concentrations, biochemical oxygen demand (BOD) and macrophyte coverage. The present study also found that phosphorus (SRP) helped to explain variance in SPEAR $_{\text {pesticides, }}$, but was much less important than insecticide TUs. While the present study did not find macrophyte coverage to be important, we measured this variable only in the 2013-2014 data group. We selected only sites that consistently had high dissolved oxygen levels, so BOD is unlikely to be a confounding factor. Bunzel et al. (2014) analyzed data from 663 stream sites in central Germany and reported that SPEAR $_{\text {pesticides }}$ values decreased with with increasing hydromorphological degradation, especially in sites with concrete channels or straight artificial stream beds. In the present study we selected sites that were not highly channelized, so this is not likely to be an important confounding factor in our analysis. 
Another factor that could affect performance of the SPEAR index but was not quantified in this study is the effect of scour during heavy runoff events, which could cause drift of benthic macroinvertebrates. During our study, heavy rainfall and high flow events sometimes occurred within the two week period prior two sample collection. However, because we analyzed each data set for each sampling event independently, and all samples for each data set were located in close proximity, all samples within each data set were subject to a similar level of antecedent flow, thus all samples within each data set would be expected to be similarly biased. Therefore, we do not expect antecedent flow events to have a large influence on the SPEAR index. In addition, an investigation where hydrodynamic stress as well as pesticide stress was investigated found that population dynamics were only influenced by runoff events that were associated with pesticide stress in addition to hydrodynamic stress (Liess and Schulz, 1999).

Crustaceans, especially amphipods in the genus Hyalella, comprised a large part of the stream invertebrate communities in the Argentine Pampas (Table S3), and also played an important role as sensitive taxa in performance of the $\mathrm{SPEAR}_{\text {pesticides }}$ index in this region. This is in contrast to

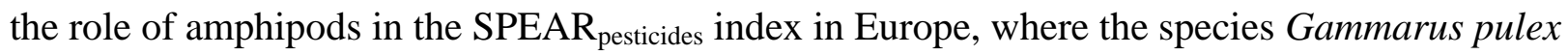
is abundant. Although G. pulex has high physiological sensitivity to pesticides, this species can

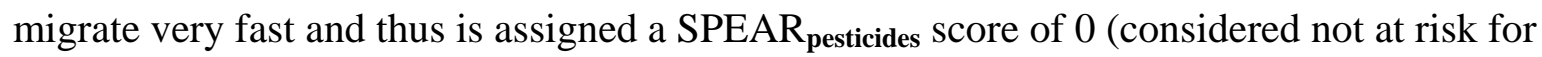
pesticides) (Liess and Von der Ohe, 2005). We were unable to find data on the migration rate of any Hyalella species, but the decrease in relative abundance of amphipods that corresponded with an increase in insecticide toxic units demonstrates that Hyalella should be considered to have overall sensitivity to insecticides. Freshwater amphipods of both the Hyalellidae and Gammaridae families are traditionally considered to be shredders of leaf litter, although recent studies have shown plasticity in their trophic levels and functional roles (Acosta and Prat, 2011). 
Although Hyalella usually was the most abundant crustacean in most samples collected in the present study, at some sites the decapod family Palaemonidae was the only crustacean present, sometimes with very high relative abundance. As shredders, amphipods play an important role in leaf litter decomposition and large reductions in their abundance may impact ecosystem functioning.

The influence of higher conductivity and chloride content on crustacean abundance is supported by previous studies, although data are somewhat limited (Kefford et al., 2016, 2012; Soucek and Kennedy, 2005). Crustaceans and other freshwater organisms are known to osmoregulate hypertonically by active transport of ions into the hemolymph, and chloride is the principal inorganic anion in the hemolymph of crustaceans (Soucek and Kennedy, 2005). Low chloride concentrations may limit distribution of some euryhaline amphipods such as Hyalella spp, and chlorides have been found to have a protective effect on sulfate toxicity to Hyalella azteca (Soucek and Kennedy, 2005). Although increased conductivity of surface water bodies has been shown to result from intensive agriculture in some regions (Kefford et al., 2016, 2012), there is little or no evidence of this conductivity effect in the regions we studied, where the conductivity levels is in streams are related to regional geology (Garcia 2016). In fact, we found that the conductivity levels were often higher and more variable in the streams located in the less intensively farmed region of La Plata (Table S2).

Although it may seem obvious that we would find that crustaceans are useful indicator organisms for pesticides because they are known to have high physiological sensitivity to pesticides, this is not necessarily true. In the Unites States some experts have questioned the appropriateness of 
using a very sensitive test organism like Hyalella, partly because Hyalella amphipods have been found in high abundance in some streams that also have high pesticide levels (Clark et al., 2015; Palmquist et al., 2011). As mentioned above, the common amphipod G. pulex has high physiological sensitivity to pesticides, but populations can recover very fast and is therefore not considered not at risk for pesticides (Liess and Von der Ohe, 2005). The findings of the present study show that at least in the case of Argentine Pampas streams, Hyalella amphipods can be a good indicator of pesticide impacts in field studies as well as in laboratory studies.

\section{Conclusions}

The present study established a correlation between insecticide TUs in stream sediments and changes in aquatic invertebrate communities of the Argentine Pampas. The SPEAR pesticides $_{\text {index }}$ consistently showed a significant decrease with increasing insecticide TUs, across all data groups. For all data sets evaluated, insecticide TU was the most important variable in explaining

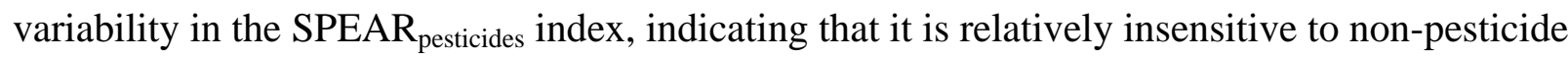
stressors.

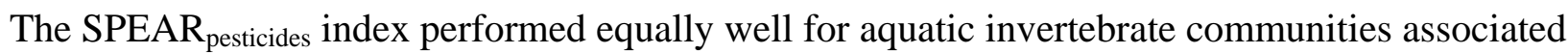
with emergent vegetation as it did for benthic invertebrate communities. This was true even

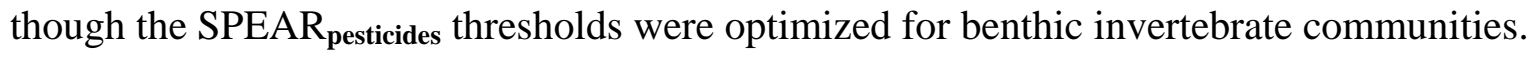
Although we consider the SPEAR threshold values to be optimized for streams in the Pampas region of Argentina based on the strong performance of the SPEAR index for all data sets in our study, the index can be further optimized as more environmental data become available in the 
region, and as trait values are refined based on studies of regional taxa. An index such as SPEAR that allows for parameterization is intrinsically expected to perform better than indices that cannot be parameterized (such as relative abundance metrics). We consider this an advantage of the SPEAR index, because it allows us to detect community-level impacts when other indices do not, and because it can be adapted and applied to different regions.

The most dramatic effect in invertebrate communities was seen on the crustaceans, which are highly sensitive to most insecticides. Crustaceans, especially amphipods in the genus Hyalella, comprised a large part of the stream invertebrate communities in the Argentine Pampas, and also played an important role as sensitive taxa in performance of the SPEAR pesticides $_{\text {index. As }}$ shredders, amphipods play an important role in leaf litter decomposition. Consequently, large reductions in their abundance may influence ecosystem functioning.

\section{Acknowledgements}

This study was supported by a grant from the Agencia Nacional de Promoción Científica y Tecnológica (Argentina - PICT 2010-0446). L. Hunt was supported primarily by fellowships from the National Science Foundation Graduate Research Fellowship Program and the Fulbright US Student Program. M. Solis provided invaluable support with field and laboratory work. J. Carter provided assistance with calculation of bioassessment metrics.

\section{References}

Barbour, M.T., Gerritsen, J., 1996. Subsampling of Benthic Samples: A Defense of the Fixed-

Count Method. J. North Am. Benthol. Soc. 15, 386. doi:10.2307/1467285 
Barton, K., 2015. Package “MuMIn.” Version 1, 18.

Beketov, M.A., Foit, K., Schäfer, R.B., Schriever, C.A., Sacchi, A., Capri, E., Biggs, J., Wells, C., Liess, M., 2009. SPEAR indicates pesticide effects in streams - Comparative use of speciesand family-level biomonitoring data. Environ. Pollut. 157, 1841-1848.

doi:10.1016/j.envpol.2009.01.021

Beketov, M.A., Liess, M., 2008. An indicator for effects of organic toxicants on lotic invertebrate communities: Independence of confounding environmental factors over an extensive river continuum. Environ. Pollut. 156, 980-987. doi:10.1016/j.envpol.2008.05.005

Bunzel, K., Liess, M., Kattwinkel, M., 2014. Landscape parameters driving aquatic pesticide exposure and effects. Environ. Pollut. 186, 90-97. doi:10.1016/j.envpol.2013.11.021

Cade, B.S., 2015. Model averaging and muddled multimodel inferences. Ecology 96, 23702382.

Carter, J., L., Resh, V.H., 2013. Analytical Approaches Used in Stream Benthic Macroinvertebrate Biomonitoring Programs of State Agencies in the United States. United States Geological Survey Open-File Report 2013-1129.

CASAFE, 2013. Cámara de Sanidad Agropecuaria y 415 Fertilizantes, Buenos Aires, Argentina. 416 http://www.casafe.org/sobrelaindustria.htm. Accessed on November 2013.

Casara, K.P., Vecchiato, A.B., Lourencetti, C., Pinto, A.A., Dores, E.F., 2012. Environmental dynamics of pesticides in the drainage area of the São Lourenço River headwaters, Mato Grosso State, Brazil. J. Braz. Chem. Soc. 23, 1719-1731. 
Castanheira, É.G., Freire, F., 2013. Greenhouse gas assessment of soybean production: implications of land use change and different cultivation systems. J. Clean. Prod. 54, 49-60. doi:10.1016/j.jclepro.2013.05.026

Chang, F.-H., Lawrence, J.E., Rios-Touma, B., Resh, V.H., 2014. Tolerance values of benthic macroinvertebrates for stream biomonitoring: assessment of assumptions underlying scoring systems worldwide. Environ. Monit. Assess. 186, 2135-2149. doi:10.1007/s10661-013-3523-6

Di Marzio, W.D., Sáenz, M.E., Alberdi, J.L., Fortunato, N., Cappello, V., Montivero, C., Ambrini, G., 2010. Environmental impact of insecticides applied on biotech soybean crops in relation to the distance from aquatic ecosystems. Environ. Toxicol. Chem. n/a-n/a. doi:10.1002/etc. 246

Ding, Y., Harwood, A.D., Foslund, H.M., Lydy, M.J., 2010. Distribution and toxicity of sediment-associated pesticides in urban and agricultural waterways from Illinois, USA. Environ. Toxicol. Chem. 29, 149-157. doi:10.1002/etc.13

Dominguez, E., Fernandez, H.R., 2009. Macroinvertebrados bentónicos. Sistemática y biología. Fundación Miguel Lillo, Tucumán, Argentina.

García Victoria Julieta. 2016. Principales factores que influyen en la retención de nutrientes en arroyos pampeanos: factores bióticos y abióticos. Doctoral thesis. University of Buenos Aires.

Grueber, C.E., Nakagawa, S., Laws, R.J., Jamieson, I.G., 2011. Multimodel inference in ecology and evolution: challenges and solutions: Multimodel inference. J. Evol. Biol. 24, 699-711. doi:10.1111/j.1420-9101.2010.02210.x 
Hagen, T.G., Douglas, R.W., 2014. Comparative chemical sensitivity between marine Australian and Northern Hemisphere ecosystems: Is an uncertainty factor warranted for water-qualityguideline setting?: Australian vs Northern Hemisphere ecosystem sensitivities. Environ. Toxicol. Chem. 33, 1187-1192. doi:10.1002/etc.2548

Helsel, D.R., 2012. Statistics for censored environmental data using Minitab and R, 2nd ed. ed, Wiley series in statistics in practice. Wiley, Hoboken, N.J.

Hladik, M.L., Kuivila, K.M., 2012. Pyrethroid insecticides in bed sediments from urban and agricultural streams across the United States. J. Environ. Monit. 14, 1838. doi:10.1039/c2em10946h

Hunt, L., Bonetto, C., Resh, V.H., Buss, D.F., Fanelli, S., Marrochi, N., Lydy, M.J., 2016. Insecticide concentrations in stream sediments of soy production regions of South America. Sci. Total Environ. 547, 114-124. doi:10.1016/j.scitotenv.2015.12.140

Jergentz, S., Mugni, H., Bonetto, C., Schulz, R., 2005. Assessment of insecticide contamination in runoff and stream water of small agricultural streams in the main soybean area of Argentina. Chemosphere 61, 817-826. doi:10.1016/j.chemosphere.2005.04.036

Jergentz, S., Mugni, H., Bonetto, C., Schulz, R., 2004a. Runoff-Related Endosulfan Contamination and Aquatic Macroinvertebrate Response in Rural Basins Near Buenos Aires, Argentina. Arch. Environ. Contam. Toxicol. 46. doi:10.1007/s00244-003-2169-8

Jergentz, S., Pessacq, P., Mugni, H., Bonetto, C., Schulz, R., 2004b. Linking in situ bioassays and population dynamics of macroinvertebrates to assess agricultural contamination in streams 
of the Argentine pampa. Ecotoxicol. Environ. Saf. 59, 133-141.

doi:10.1016/j.ecoenv.2004.06.007

Kwok, K.W., Leung, K.M., Lui, G.S., Chu, V.K., Lam, P.K., Morritt, D., Maltby, L., Brock, T., Van den Brink, P.J., Warne, M.S.J., others, 2007. Comparison of tropical and temperate freshwater animal species' acute sensitivities to chemicals: Implications for deriving safe extrapolation factors. Integr. Environ. Assess. Manag. 3, 49-67.

Laabs, V., Amelung, W., Pinto, A.A., Wantzen, M., da Silva, C.J., Zech, W., 2002. Pesticides in surface water, sediment, and rainfall of the northeastern Pantanal basin, Brazil. J. Environ. Qual. $31,1636-1648$.

Liess, M., Schäfer, R.B., Schriever, C.A., 2008. The footprint of pesticide stress in communities-Species traits reveal community effects of toxicants. Sci. Total Environ. 406, 484-490. doi:10.1016/j.scitotenv.2008.05.054

Liess, M., Von der Ohe, P.C.D., 2005. Analyzing effects of pesticides on invertebrate communities in streams. Environ. Toxicol. Chem. 24, 954-965.

Liess, M., Schulz, R., 1999. Linking insecticide contamination and population response in an agricultural stream. Environ. Toxicol. Chem. 18, 1948-1955.

Marino, D., Ronco, A., 2005. Cypermethrin and Chlorpyrifos Concentration Levels in Surface Water Bodies of the Pampa Ondulada, Argentina. Bull. Environ. Contam. Toxicol. 75, 820-826. doi:10.1007/s00128-005-0824-7 
Merritt, R.W., Cummins, K.W., 2008. An Introduction to the Aquatic Insects of North America, 4th ed. Kendall Hunt Publishing.

Mugni, H., Paracampo, A., Marrochi, N., Bonetto, C., 2013. Acute toxicity of cypermethrin to the non target organism Hyalella curvispina. Environ. Toxicol. Pharmacol. 35, 88-92. doi:10.1016/j.etap.2012.11.008

Mugni, H., Ronco, A., Bonetto, C., 2011. Insecticide toxicity to Hyalella curvispina in runoff and stream water within a soybean farm (Buenos Aires, Argentina). Ecotoxicol. Environ. Saf. 74, 350-354. doi:10.1016/j.ecoenv.2010.07.030

Mullen, K., Ardia, D., Gil, D.L., Windover, D., Cline, J., 2011. DEoptim: An R package for global optimization by differential evolution. J. Stat. Softw. 40, 1-26.

Münze, R., Orlinskiy, P., Gunold, R., Paschke, A., Kaske, O., Beketov, M.A., Hundt, M., Bauer, C., Schüürmann, G., Möder, M., Liess, M., 2015. Pesticide impact on aquatic invertebrates identified with Chemcatcher® passive samplers and the SPEARpesticides index. Sci. Total Environ. 537, 69-80. doi:10.1016/j.scitotenv.2015.07.012

Nordborg, M., Cederberg, C., Berndes, G., 2014. Modeling Potential Freshwater Ecotoxicity Impacts Due to Pesticide Use in Biofuel Feedstock Production: The Cases of Maize, Rapeseed, Salix , Soybean, Sugar Cane, and Wheat. Environ. Sci. Technol. 48, 11379-11388. doi:10.1021/es502497p

Orlinskiy, P., Münze, R., Beketov, M., Gunold, R., Paschke, A., Knillmann, S., Liess, M., 2015. Forested headwaters mitigate pesticide effects on macroinvertebrate communities in streams: 
Mechanisms and quantification. Sci. Total Environ. 524-525, 115-123.

doi:10.1016/j.scitotenv.2015.03.143

Pengue, W., 2000. Cultivos transgenicos >Hacia donde vamos? Lugar Editorial S. A., Buenos Aires.

Rasmussen, J.J., Baattrup-Pedersen, A., Larsen, S.E., Kronvang, B., 2011. Local physical habitat quality cloud the effect of predicted pesticide runoff from agricultural land in Danish streams. J. Environ. Monit. 13, 943. doi:10.1039/c0em00745e

Rubach, M.N., Baird, D.J., Van den Brink, P.J., 2010. A new method for ranking mode-specific sensitivity of freshwater arthropods to insecticides and its relationship to biological traits. Environ. Toxicol. Chem. 29, 476-487. doi:10.1002/etc.55

Schäfer, R.B., Caquet, T., Siimes, K., Mueller, R., Lagadic, L., Liess, M., 2007. Effects of pesticides on community structure and ecosystem functions in agricultural streams of three biogeographical regions in Europe. Sci. Total Environ. 382, 272-285. doi:10.1016/j.scitotenv.2007.04.040

Schäfer, R.B., Pettigrove, V., Rose, G., Allinson, G., Wightwick, A., von der Ohe, P.C., Shimeta, J., Kühne, R., Kefford, B.J., 2011. Effects of Pesticides Monitored with Three Sampling Methods in 24 Sites on Macroinvertebrates and Microorganisms. Environ. Sci. Technol. 45, 1665-1672. doi:10.1021/es103227q

Schäfer, R.B., von der Ohe, P.C., Rasmussen, J., Kefford, B.J., Beketov, M.A., Schulz, R., Liess, M., 2012. Thresholds for the Effects of Pesticides on Invertebrate Communities and Leaf 
Breakdown in Stream Ecosystems. Environ. Sci. Technol. 46, 5134-5142.

doi:10.1021/es2039882

Soucek, D.J., Kennedy, A.J., 2005. Effects of hardness, chloride, and acclimation on the acute toxicity of sulfate to freshwater invertebrates. Environ. Toxicol. Chem. 24, 1204-1210.

Von der Ohe, P.C., Liess, M., 2004. Relative sensitivity distribution of aquatic invertebrates to organic and metal compounds. Environ. Toxicol. Chem. 23, 150-156.

Wiberg-Larsen, P., Graeber, D., Kristensen, E.A., Baattrup-Pedersen, A., Friberg, N., Rasmussen, J.J., 2016. Trait Characteristics Determine Pyrethroid Sensitivity in Nonstandard Test Species of Freshwater Macroinvertebrates: A Reality Check. Environ. Sci. Technol. 50, 4971-4978. doi:10.1021/acs.est.6b00315

You, J., Schuler, L.J., Lydy, M.J., 2004. Acute Toxicity of Sediment-Sorbed Endrin, Methoxychlor, and Endosulfan to Hyalella azteca and Chironomus tentans. Bull. Environ. Contam. Toxicol. 73. doi:10.1007/s00128-004-0451-8 
